\title{
Capacidade de Gestão de Políticas Sociais: metodologia de construção e validação de tipologia para análise da oferta dos Serviços Socioassistenciais*
}

Rafael Siqueira Barreto

Alexander Cambraia Nascimento $\mathrm{Vaz}^{2}$

Paulo de Martino Jannuzzi ${ }^{3}$

1 Mestre em Economia do Setor Público/UnB, Especialista em Políticas Públicas e Gestão Governamental.

2 Mestre em Ciência Política pela UFMG, Coordenador-Geral do Departamento de Monitoramento da Secretaria de Avaliação e Gestão da Informação do MDS.

3 Professor da Escola Nacional de Ciências Estatísticas do IBGE, colaborador da Escola Nacional de Administração Pública e pesquisador do CNPq no projeto PQ "Informação estatística e sistemas de monitoramento e avaliação de Políticas e programas sociais no Brasil e América Latina".

Os autores agradecem André Luiz Lara Resende Saraiva pela colaboração na elaboração desse artigo.

\section{Introdução}

Falta de estrutura organizacional e deficiências de capacidade de gestão são achados recorrentes nos estudos sobre implementação e efetividade de políticas e programas sociais no País. Propostas meritórias de programas, com desenhos lógicos consistentes "em tese", podem ser inviabilizadas pelos problemas de implementação decorrentes de baixa capacidade de gestão de agentes encarregados da operação em um dos "nós críticos" do programa.
Nessa perspectiva, frente ao volume de recursos e complexidade na operação de programas sociais no Brasil, é cada vez mais importante dispor-se de indicadores ou tipologias que permitam aos gestores anteciparem situações de baixa capacidade de implementação de ações. Tal informação pode ser crucial no desenho do arranjo operacional do programa ou na sua implementação, seja para seleção de situações-alvo mais propícias ou agentes mais preparados na operação do pro- 
grama, seja para antecipar a necessidade de ações específicas de capacitação gerencial e estruturação física dos entes envolvidos na implementação.

No caso brasileiro, o município é o agente operador de um conjunto amplo de políticas sociais na educação, saúde e assistência social. Nos últimos dez anos, os municípios têm atuado na gestão da Política Nacional de Assistência Social (PNAS). Tal Política e sua regulamentação na Norma Operacional Básica (NOB/2005) do Sistema Único de Assistência Social (SUAS) caracterizam-se pela ênfase na descentralização administrativa e, por conseguinte, na estruturação da gestão local como condição necessária para a estruturação permanente de serviços nos níveis de proteção social básica e especial, executados com o auxílio complementar de transferências fundo a fundo da esfera federal para os municípios.

De modo a contribuir para estudos de implementação dos programas, serviços e benefícios da PNAS, este texto apresenta a metodologia e validação da Tipologia Analítica de Capacidade de Gestão da Assistência Social (TACGAS), partindo-se do pressuposto de que a execução descentralizada de serviços depende da capacidade instalada em âmbito municipal em termos de recursos humanos, financeiros e institucionais.
Além desta Introdução, o presente artigo está divido em mais quatro seções. A seção 2 apresenta um breve retrospecto de dois condicionantes históricos relevantes: a importância crescente do monitoramento e da avaliação na ação governamental brasileira e, especificamente na temática da assistência social, a relevância e o enfoque conferidos recentemente à gestão nesta seara. Na seção seguinte é explicitada a metodologia de construção da TACGAS. A seção 4 apresenta os resultados obtidos, com destaque para a aferição da relação entre a tipologia e a efetiva oferta de serviços socioassistenciais. Por fim, nas considerações finais procede-se a uma síntese dos principais achados, bem como limitações aplicáveis e sugestões de trabalho futuro.

\section{Capacidade de gestão em assistência social TACGAS: do "constructo normativo" à tipologia operacional}

Nesta seção apresentar-se-á a Tipologia Analítica de Capacidade de Gestão da Assistência Social, doravante TACGAS. Essencialmente, trata-se de tipologia cuja finalidade consiste na avaliação da capacidade dos municípios brasileiros de gerir políticas, recursos e apresentar resultados na área de assistência social. 
Neste âmbito, a TACGAS busca servir de aporte ao planejamento público e ao fortalecimento das políticas sociais no nível local, por meio do estabelecimento de padrões e perfis de classificação dos municípios brasileiros quanto às suas respectivas capacidade de gestão e administração na área de assistência social, por meio da análise de um leque de dimensões e fatores correlatos à temática.

Preliminarmente, cabe ressaltar que as fontes de informações que embasaram, no que se refere à escolha dos dados, a construção da TACGAS foram os Suplementos 2005 e 2009 da Assistência Social da Pesquisa de Informações Básicas Municipais (MUNIC), elaborada pelo Instituto Brasileiro de Geografia e Estatística (IBGE).

Não obstante haja outras pesquisas capazes de municiar uma análise sobre a capacidade de gestão dos municípios no âmbito da assistência social, nenhuma delas agrega as características do suplemento supracitado em termos de abrangência (5.565 municípios) e foco na temática. À guisa de ilustração, na edição de 2009 foram coletados dados sobre a caracterização e infraestrutura do órgão gestor da política de assistência social, recursos humanos, legislação e instrumentos de planejamento, conselhos municipais, convênios e parcerias, recursos financeiros e serviços socioassistenciais, caracterizando a Munic como uma pesquisa institucional e de registros administrativos da gestão pública municipal que procura fazer um levantamento detalhado de in- formações sobre a estrutura, a dinâmica e o funcionamento das instituições públicas municipais.

Especificamente, a TACGAS foi construída levando em consideração uma perspectiva multivariada e pretende expressar, de maneira sintética, a situação dos municípios brasileiros no tocante a algumas dimensões específicas, geralmente percebidas como relevantes indicadores da capacidade de gestão e administração de políticas públicas.

Com este intuito, a concepção da TACGAS está embasada em princípios teóricos e normativos expressamente ratificados pela Norma Operacional Básica de Recursos Humanos (NOB/RH) do SUAS, como o pressuposto de que a qualificação profissional, consubstanciada seja no aumento da escolaridade, seja na melhoria do vínculo empregatício dos profissionais atuantes na assistência social, é condição basilar para a adequada operacionalização dos serviços socioassistenciais em nosso País.

Neste sentido, a formulação da TACGAS iniciou-se pela seleção de suas dimensões constituintes, cada uma abarcando um rol específico de variáveis cujo atual arcabouço normativo sugere que sejam determinantes com suficiente poder de discriminação das condições de operacionalização da assistência social nos municípios.

De forma geral, as dimensões foram construídas tendo-se como lógica estruturante 


\section{- GRÁFICO 1: DIMENSÕES COMPONENTES DA TACGAS}

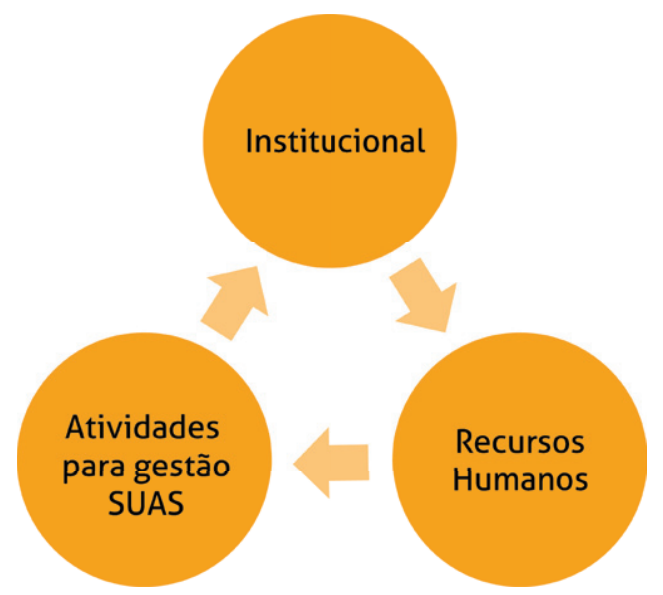

Fonte: Elaboração própria.

a distinção entre os agentes da ação social local, as atividades de gestão em si da assistência social e o ambiente, em sentido amplo, no qual essas atividades se desenvolvem.

Esquematicamente, as dimensões constituintes da TACGAS encontram-se representadas no gráfico 1.

Nesse contexto, a dimensão Institucional concerne ao ambiente ou contexto de fatores disponíveis para a gestão da assistência social em âmbito municipal. Destarte, abarca os aspectos de infraestrutura física, arcabouço normativo e recursos financeiros.
A infraestrutura física disponibilizada para as atividades de planejamento e gestão em assistência social tem sua relevância elementar como condicionante na qualidade e escala das atividades de gestão desempenhadas, sendo reconhecida em diversas instruções normativas e cadernos de orientações técnicas, inclusive na seara específica da assistência social. ${ }^{4}$

No caso da TACGAS, este aspecto foi representado por meio da variável Caracterização do Órgão Gestor, cuja categorização varia desde a conformação da assistência social como secretaria exclusiva até os municípios onde a gestão dessa área é compartilhada com outros setores.

4 Vide bibliografia para exemplo de estudo efetuado sobre espaços mínimos para sua conformação às atividades desempenhadas nos Centros de Referência da Assistência Social (CRAS), constantes do documento "Características espaciais necessárias ao CRAS para adequação às prescrições normativas no âmbito do SUAS e à integração das políticas do MDS".

Revista Brasileira de Monitoramento e Avaliação | Número 3 | Janeiro-Junho de 2012 
A suposição aqui é de que os órgãos com estrutura exclusiva tenderão a apresentar resultados superiores àqueles obtidos por entes que têm de dividir seus respectivos instrumentos de trabalho, como salas, computadores, telefones e outros.

No concernente ao arcabouço normativo, aqui referido como Legislação e Instrumentos de Gestão, emprega-se o pressuposto de que a qualificação da gestão dos serviços e programas de políticas públicas advém da estabilidade de sua operacionalização e, principalmente, de seu acompanhamento, monitoramento e avaliação ao longo do tempo. Esses processos permitem ao gestor otimizar o emprego de recursos, sejam físicos, financeiros e/ou humanos, bem como realizar eventuais correções nas atividades em curso, viabilizando o planejamento contínuo e a prevenção de erros e/ou resultados aquém do esperado. A operacionalização dessa subdimensão é realizada através de duas variáveis: Freqüência do Monitoramento do Plano Municipal de Assistência Social (PMAS) e uso do Cadastro Único pelo órgão gestor.

A primeira variável informa não somente a existência ou não de um Plano Municipal de Assistência Social, como sua frequência, desde que existente, de monitoramento/acompanhamento. A importância de um plano dessa estirpe é reconhecida e ressaltada pela própria NOB/2005, a qual instituiu o PMAS como pré-requisito para habilitação à gestão municipal de recursos. O PMAS constitui-se fundamentalmente em instrumento que confere previsibilidade e, principalmente, concretude ao planejamento das ações no campo, ao enunciar as metas e a escala dos serviços socioassistenciais a serem ofertados, que servirão de referencial para aferição da eficácia e eficiência dos resultados atingidos ao término de cada exercício, quando contrapostos aos dados informados anualmente pelos municípios no demonstrativo sintético de execução financeira.

Obviamente, a elaboração original de cada PMAS não é suficiente em si, devendo ser atualizada periodicamente de forma a revelar o seu uso efetivo na condução das políticas de assistência social. Este aspecto, conjuntamente com a relevância em si do instrumento, justifica a incorporação da variável relativa à frequência de seu monitoramento.

Por sua vez, hoje o Cadastro Único é reconhecido como ferramenta basilar para a identificação, caracterização e seleção de públicos-alvo para políticas destinadas à população de baixa renda e em situação de vulnerabilidade social. Neste sentido, o controle, a atualização dos dados e a efetiva utilização são tarefas significativas sob a ótica da capacidade municipal de planejamento e de focalização de políticas na seara da assistência social.

O último fator relativo à dimensão Institucional refere-se aos Recursos Financeiros, os quais, logicamente, são componente fundamental para a consecução de atividades e ações para qualquer tipo de política pública (ou mesmo para projetos privados). A subdimensão financeira é representada por duas variáveis: a existência de Fundo Municipal de Assistência So- 
cial (FMAS) como unidade orçamentária e a vinculação de percentual do orçamento municipal para utilização compulsória no campo da assistência social.

A primeira variável permite aferir não somente a existência de um fundo ligado à assistência social, como também sua caracterização como unidade orçamentária. Essa qualificação é relevante, pois revela a existência de autonomia no tocante à movimentação de recursos, prescindindo, portanto, de outras instâncias para a execução financeira. Este fator tende a colaborar para a previsibilidade, transparência e planejamento nos gastos efetuados nessa seara, bem como consubstancia-se em diretriz expressa constante da NOB, no capítulo que versa sobre o financiamento da assistência social.

Complementarmente, a segunda variável ratifica os componentes de planejamento, previsibilidade e, principalmente, transparência nos gastos da assistência social, os quais tendem a ser mais presentes em administrações municipais que se dispõem a vincular percentual de seu orçamento para consecução de gastos na seara em tela.

Resumidamente, a dimensão Institucional e seus componentes estão discriminados no gráfico 2.

\section{- GRÁFICO 2: COMPONENTES DA DIMENSÃO INSTITUCIONAL TACGAS}
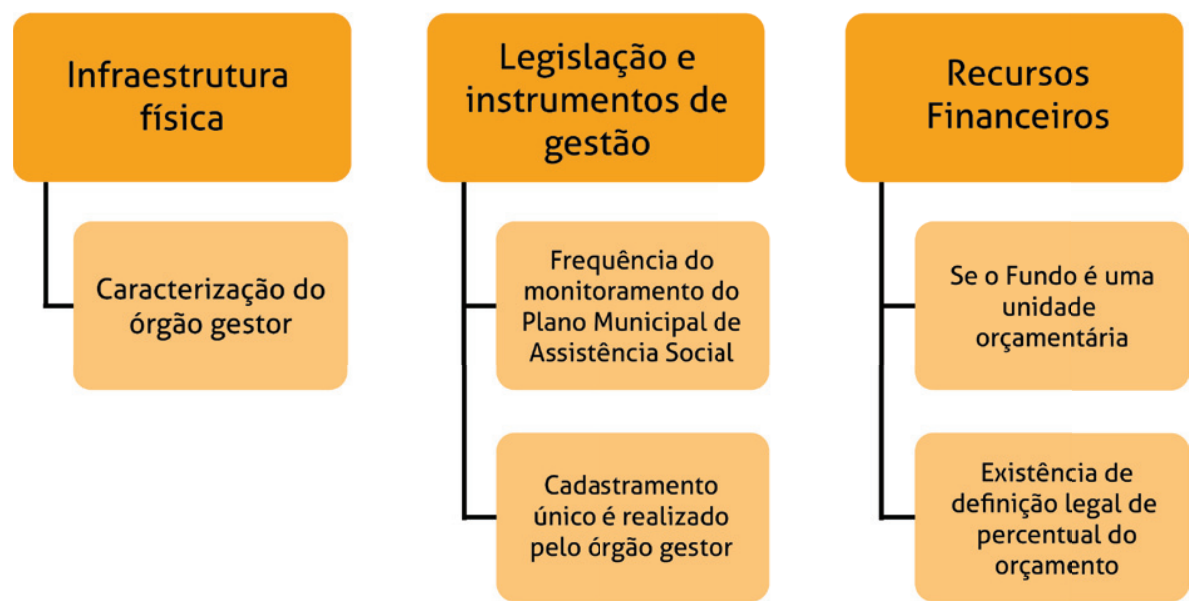

Fonte: Elaboração própria.

Revista Brasileira de Monitoramento e Avaliação | Número 3 | Janeiro-Junho de 2012

Capacidade de Gestão de Políticas Sociais: metodologia de construção e validação de tipologia para análise da oferta dos Serviços Socioassistenciais 
Por seu turno, outra dimensão também contemplada pela TACGAS e de significativa relevância para a gestão de políticas consiste nos Recursos Humanos disponíveis.

Efetivamente, a quantidade e qualificação dos profissionais que lidam com as políticas e respondem pela sua operacionalização podem ser variáveis determinantes para o sucesso ou fracasso dessas políticas. Neste caso, devido ao amplo espectro do fenômeno a ser mensurado, optou-se por sua ramificação em duas subdimensões: instrução/escolaridade e vínculo empregatício/composição da força de trabalho.

O grau de escolaridade foi utilizado como aproximação para se representar as habilidades e tipos de expertise dos técnicos e indivíduos que atuam na área da assistência social nos municípios. Sua utilização na composição da TACGAS baseou-se no emprego de duas variáveis.

Em primeiro lugar, a escolaridade do titular do órgão gestor foi considerada em função de sua importância na determinação das habilidades do principal administrador na gestão da temática. A segunda variável selecionada refere-se ao grau de instrução do pessoal ocupado na área de assistência social , o qual, de forma análoga, subentende-se como indicativo poderoso para a mensuração da expertise dos técnicos e indivíduos envolvidos no trabalho e gestão da área. De fato, a relevância da formação em nível superior e de capacitação continuada dos profissionais da assistência social é reiteradamente destacada na NOB-RH do SUAS.
A segunda subdimensão dos Recursos Humanos, denominada de Vínculo/ Composição, presta-se tentativamente à mensuração do grau de comprometimento e rotatividade dos trabalhadores de assistência social em nível local, bem como seu adequado dimensionamento. Sua operacionalização assenta-se em dois indicadores.

O indicador de vínculo do pessoal ocupado na área de assistência social mensura o percentual de funcionários celetistas e/ou estatutários ocupados nas atividades de campo. Quanto maior a proporção de funcionários contratados nessas modalidades, depreende-se que tende a ser menor o rodízio de trabalhadores atuantes nessa seara.

Efetivamente, a rotatividade de profissionais pode constituir grave problema para a gestão de políticas, uma vez que tende a comprometer a estabilidade de atendimentos, o acúmulo de conhecimentos e o planejamento de uma forma geral. Por conseguinte, espera-se que municípios que tenham maior proporção de funcionários com vínculos empregatícios mais estáveis, como os celetistas ou concursados, apresentem melhores resultados em termos de administração.

Essa percepção coaduna-se com o princípio norteador da NOB-RH do SUAS, a qual preceitua a formação progressiva de um maior número de servidores exclusivos para atuação na área de assistência social.

Nesse sentido, o segundo indicador também lida com uma proporção concernente ao dimensionamento da força de trabalho, por meio do número de funcionários da 


\section{GRÁFICO 3: COMPONENTES DA DIMENSÃO RECURSOS HUMANOS TACGAS}

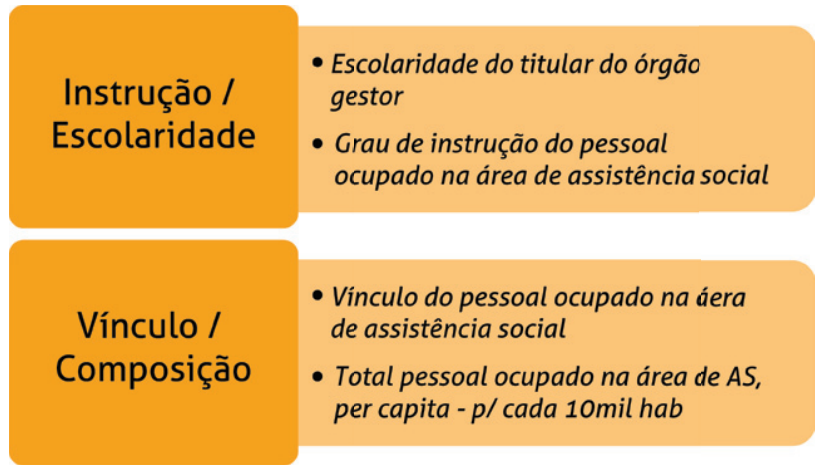

Fonte: Elaboração própria.

área para cada grupo de dez mil habitantes, denominada de total de pessoal ocupado na assistência social.

Essa proporção é relevante porque permite a comparação entre os municípios por meio de uma escala comum, consubstanciada no denominador de grupos de dez mil habitantes. Uma visão geral da dimensão Recursos Humanos é apresentada no esquema acima:

A última dimensão componente da TACGAS consiste nas Atividades para gestão do SUAS, que busca aferir a aderência das atividades desempenhadas nessa seara aos critérios de efetividade, eficiência e eficácia. Ao contrário das duas dimensões precedentes, pretende-se aqui mensurar a adequação não dos insumos, mas das atividades-meio perpetradas na assistência social que sejam boas práticas de gestão.

Com esse intuito, fez-se uso de duas variáveis. A primeira, relativa à utilização de sistemas informatizados para gestão, monitoramento e avaliação, em função da percepção disseminada de que o uso de recursos tecnológicos como ferramental de administração contribui para mais racionalidade, parametrização e celeridade na utilização de recursos, bem como potencializa a obtenção de resultados ótimos pelas políticas por meio de sua contínua revisão e aperfeiçoamento. Efetivamente, se as atividades de monitoramento e avaliação já constituem fatores relevantes nesse contexto, pode-se dizer que sua consecução por meio de recursos tecnológicos potencializa seus respectivos efeitos benéficos. 
A segunda variável de operacionalização consiste no Monitoramento de serviços socioassistenciais mantidos em convênio com organizações/entidades da assistência social. De fato, pode-se constatar que a estruturação dos programas e serviços das políticas públicas ocorre, frequentemente, com a parceria de organizações e/ou entidades privadas que detêm expertise na área.

De forma geral, essas parcerias são benéficas para a área, seja em função do envolvimento dos contratados com a temática, seja em potenciais ganhos de sinergia na oferta de serviços. Contudo, de maneira a se garantir a transparência e responsabilidade na gestão pública, evidencia-se necessário o acompanhamento sistemático das ações desenvolvidas por esses parceiros.

Destarte, supõe-se que municípios nos quais este acompanhamento é realizado tendem a apresentar melhores resultados de gestão, devido à racionalização dos gastos e à exigência de resultados concretos. Uma vez mais, também a relevância desse componente da TACGAS, ou seja, do monitoramento dos serviços socioassistenciais e da utilização de ferramental tecnológico para sua consecução, é reconhecida pela NOB/SUAS, a qual reserva uma seção exclusiva no capítulo de instrumentos de gestão para a "gestão da informação, monitoramento e avaliação".

Sinteticamente, o gráfico abaixo expõe um panorama da dimensão Atividades para Gestão do SUAS.

A análise empírica da combinação das várias subdimensões e variáveis constituintes da TACGAS levou à conformação de cinco perfis ou níveis de capacidade de gestão. Esses perfis são ordenados de forma crescente segundo seu grau de estruturação na seara da assistência social e apresentados no Quadro 1, cuja validação é discutida na seção seguinte.

\section{GRÁFICO 4: COMPONENTES DA DIMENSÃO ATIVIDADES PARA GESTÃO DO SUAS - TACGAS}

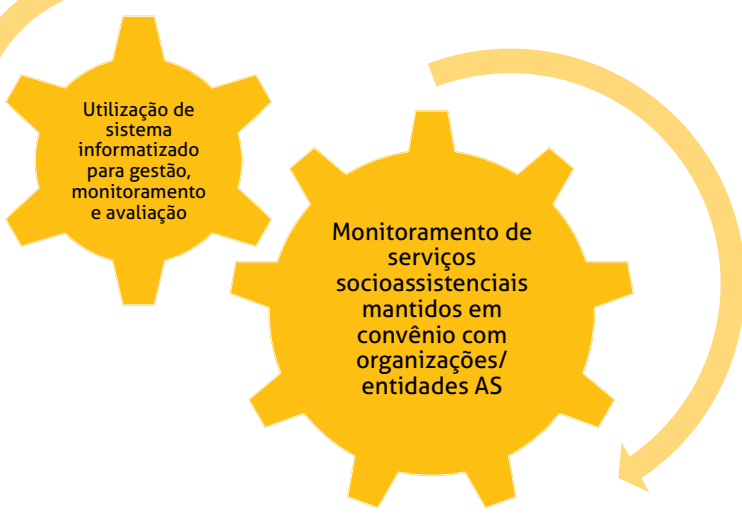




\section{- ouAdRO 1: NÍVEIS DE CAPACIDADE DE GESTÃo EM ASSISTÊNCIA SOCIAL, CONFORME TACGAS}

\begin{tabular}{|c|c|c|c|c|c|c|c|}
\hline Dimensão & $\begin{array}{l}\text { Subdimen- } \\
\text { são }\end{array}$ & Variáveis & $\begin{array}{l}\text { Nivel de } \\
\text { Acesso }\end{array}$ & $\begin{array}{c}\text { Nível } \\
\text { Ascendente }\end{array}$ & $\begin{array}{l}\text { Nível Inter } \\
\text { mediário }\end{array}$ & $\begin{array}{c}\text { Nível } \\
\text { Avançado }\end{array}$ & $\begin{array}{c}\text { Nível } \\
\text { Referencial }\end{array}$ \\
\hline \multirow{5}{*}{$\begin{array}{l}\text { Institucio- } \\
\text { nal }\end{array}$} & $\begin{array}{l}\text { Infraestru- } \\
\text { tura } \\
\text { Física }\end{array}$ & $\begin{array}{c}\text { Caracterização } \\
\text { do } \\
\text { órgão gestor }\end{array}$ & $\begin{array}{l}\text { Não possui } \\
\text { estrutura }\end{array}$ & $\begin{array}{c}\text { Estrutura } \\
\text { existente, } \\
\text { mas não } \\
\text { necessa- } \\
\text { riamente } \\
\text { exclusiva }\end{array}$ & $\begin{array}{c}\text { Estrutura } \\
\text { existente, } \\
\text { mas não } \\
\text { necessa- } \\
\text { riamente } \\
\text { exclusiva }\end{array}$ & $\begin{array}{l}\text { Secretaria } \\
\text { municipal } \\
\text { exclusiva }\end{array}$ & $\begin{array}{l}\text { Secretaria } \\
\text { municipal } \\
\text { exclusiva }\end{array}$ \\
\hline & \multirow{2}{*}{$\begin{array}{l}\text { Legisla- } \\
\text { ção e } \\
\text { Instru- } \\
\text { mentos } \\
\text { de Gestão }\end{array}$} & $\begin{array}{c}\text { Frequência do } \\
\text { monit. do plano } \\
\text { municipal }\end{array}$ & Não efetua & Não efetua & Anual & $\begin{array}{l}\text { Semestral } \\
\text { Bimestral }\end{array}$ & $\begin{array}{c}\text { Semestral } \\
\text { Mensal }\end{array}$ \\
\hline & & $\begin{array}{l}\text { Uso do Cad. } \\
\text { Único pelo órgão } \\
\text { gestor }\end{array}$ & Não & Sim & Sim & Sim & Sim \\
\hline & \multirow{2}{*}{$\begin{array}{c}\text { Recursos } \\
\text { Financeiros }\end{array}$} & $\begin{array}{l}\text { Se o Fundo é } \\
\text { uma unidade } \\
\text { orçamentária }\end{array}$ & Não & Não & Sim & Sim & Sim \\
\hline & & $\begin{array}{c}\text { Existência de } \\
\text { def. legal de \% } \\
\text { do orçamento }\end{array}$ & Não & Não & Não & Não & Sim \\
\hline \multirow{4}{*}{$\begin{array}{l}\text { Recursos } \\
\text { Humanos }\end{array}$} & \multirow{2}{*}{$\begin{array}{l}\text { Instrução / } \\
\text { Escolari- } \\
\text { dade }\end{array}$} & $\begin{array}{l}\text { Escolaridade do } \\
\text { titular do órgão } \\
\text { gestor }\end{array}$ & $\begin{array}{l}\text { Ensino } \\
\text { médio } \\
\text { incompleto } \\
\text { ou inferior }\end{array}$ & $\begin{array}{l}\text { Ensino mé- } \\
\text { dio completo } \\
\text { ou superior }\end{array}$ & $\begin{array}{l}\text { Ensino } \\
\text { superior } \\
\text { completo }\end{array}$ & $\begin{array}{l}\text { Ensino } \\
\text { superior } \\
\text { completo }\end{array}$ & $\begin{array}{c}\text { Pós-gradu- } \\
\text { ação }\end{array}$ \\
\hline & & $\begin{array}{c}\text { \% ponderado } \\
\text { grau de instru- } \\
\text { ção }\end{array}$ & $\begin{array}{l}\text { Na média, } \\
\text { ensino fun- } \\
\text { damental } \\
\text { incompleto } \\
\text { ou inferior }\end{array}$ & $\begin{array}{l}\text { Na média, } \\
\text { ensino } \\
\text { fundamental } \\
\text { completo }\end{array}$ & $\begin{array}{l}\text { Na média, } \\
\text { ensino } \\
\text { médio in- } \\
\text { completo }\end{array}$ & $\begin{array}{l}\text { Na média, } \\
\text { ensino } \\
\text { médio in- } \\
\text { completo }\end{array}$ & $\begin{array}{l}\text { Na média, } \\
\text { ensino } \\
\text { médio } \\
\text { completo }\end{array}$ \\
\hline & \multirow[t]{2}{*}{$\begin{array}{l}\text { Vínculo / } \\
\text { Composi- } \\
\text { ção }\end{array}$} & $\begin{array}{l}\text { \% funcs. estatu- } \\
\text { tários/celetistas }\end{array}$ & $\begin{array}{c}\text { Abaixo de } \\
10 \%\end{array}$ & $\begin{array}{l}\text { Acima de } \\
10 \% \text { (> } 100 \\
\text { mil hab.) e } \\
\text { acima de } \\
\text { 15\%(< } 100 \\
\text { mil hab.) }\end{array}$ & $\begin{array}{l}\text { Acima de } \\
15 \% \text { (> } 100 \\
\text { mil hab.) e } \\
\text { acima de } \\
20 \%(<100 \\
\text { mil hab.) }\end{array}$ & $\begin{array}{c}\text { Acima de } \\
20 \% \text { (> } \\
100 \text { mil } \\
\text { hab.) e } \\
\text { acima de } \\
25 \%(< \\
100 \text { mil } \\
\text { hab.) }\end{array}$ & $\begin{array}{c}\text { Acima de } \\
25 \% \text { (> } \\
100 \text { mil } \\
\text { hab.) e } \\
\text { acima de } \\
30 \%(< \\
100 \text { mil } \\
\text { hab.) }\end{array}$ \\
\hline & & $\begin{array}{c}\text { \% funcs. } \\
\text { ocupados na } \\
\text { assistência social } \\
\text { (per capita } 10 \\
\text { mil hab.) }\end{array}$ & $\begin{array}{l}\text { Abaixo de } \\
1 \text { (> } 100 \\
\text { mil hab.) e } \\
\text { abaixo de } 4 \\
\text { (< } 100 \text { mil } \\
\text { hab.) }\end{array}$ & $\begin{array}{l}\text { Acima de } 1 \\
(>100 \text { mil } \\
\text { hab.) e acima } \\
\text { de } 4 \text { (< } 100 \\
\text { mil hab.) }\end{array}$ & $\begin{array}{c}\text { Acima de } \\
2 \text { (> } 100 \\
\text { mil hab.) e } \\
\text { acima de } 6 \\
\text { (< } 100 \text { mil } \\
\text { hab.) }\end{array}$ & $\begin{array}{c}\text { Acima de } \\
3 \text { (> } 100 \\
\text { mil hab.) e } \\
\text { acima de } 8 \\
\text { (< } 100 \text { mil } \\
\text { hab.) }\end{array}$ & $\begin{array}{l}\text { Acima de } \\
4 \text { (> } 100 \\
\text { mil hab.) e } \\
\text { acima de } \\
10 \text { (< } 100 \\
\text { mil hab.) }\end{array}$ \\
\hline \multirow{2}{*}{\multicolumn{2}{|c|}{$\begin{array}{l}\text { Atividades para } \\
\text { Gestão do SUAS }\end{array}$}} & $\begin{array}{l}\text { Utilização de } \\
\text { SI para gestão, } \\
\text { monitoramento } \\
\text { e avaliação }\end{array}$ & Não & Não & Não & Sim & Sim \\
\hline & & $\begin{array}{c}\text { Monit. convênios } \\
\text { com org./ent. }\end{array}$ & Não & Não & Não & Sim & Sim \\
\hline
\end{tabular}

Fonte dados: IBGE Munic 2005/2009 - Suplemento AS

Revista Brasileira de Monitoramento e Avaliação | Número 3 | Janeiro-Junho de 2012

Capacidade de Gestão de Políticas Sociais: metodologia de construção e validação de tipologia para análise da oferta dos Serviços Socioassistenciais 


\section{Caracterização \\ Empírica e Validação da TACGAS}

Subsequentemente à formulação da tipologia em si, o passo seguinte elementar era contrapô-la à evolução recente do setor da assistência social e, em particular, à oferta de serviços socioassistenciais, a fim de aferir sua efetiva consistência no encadeamento teórico de que maior capacidade de gestão deveria colaborar para viabilizar o aumento da escala e a diversificação da gama de serviços disponibilizados na seara da assistência social.

Ao se adotar o critério da TACGAS para classificação dos municípios, observa-se que, para 2005 e 2009, existe uma concentra-

ção de municípios nos perfis de acesso e ascendente, mas com uma clara melhoria no período. Há redução da participação dos municípios do perfil 1 de mais de 50\% para $37 \%$, e com a duplicação das localidades enquadradas no perfil 3, que de $11,5 \%$ passaram a representar $23,7 \%$ do total.

Na média, em 2005 os municípios estavam a meio caminho entre os níveis de acesso e ascendente, enquanto que em 2009 já alcançavam o nível ascendente. Nos níveis superiores também houve melhora, mas ainda representam um pequeno percentual do total de municípios brasileiros.

\section{GRÁFICO 5: OUUANTIDADE DE MUNICÍPIOS POR CATEGORIA DA TACGAS, POR ANO}

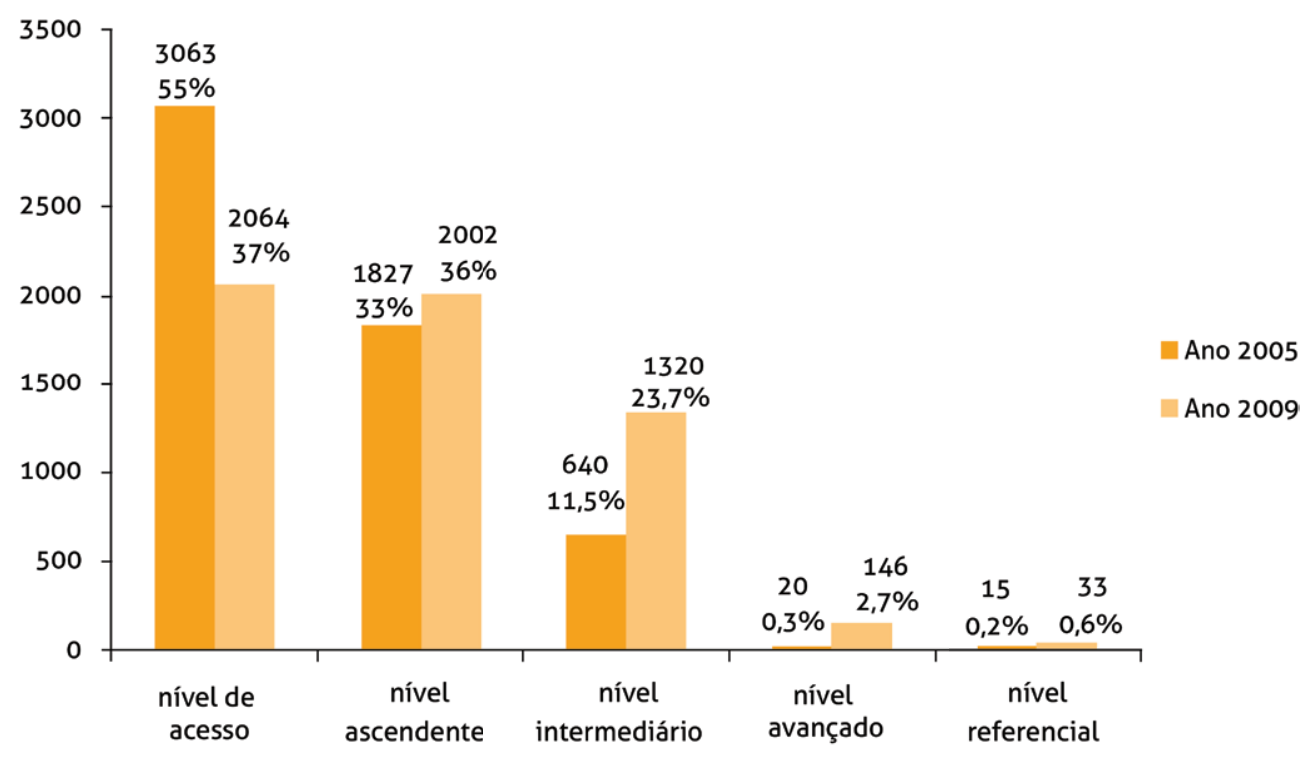


Esses resultados são consistentes quando analisados em perspectiva histórica se considerarmos que, em 2005, a assistência social como política pública sistêmica, consubstanciada no SUAS e no bojo do reconhecimento do acesso aos serviços organizados no âmago desse sistema como direitos sociais, encontrava-se em fase de estruturação, uma vez que a própria PNAS fora promulgada no ano anterior e a NOB/ SUAS seria aprovada em 2005.

Por outro lado, em 2009 o SUAS avançou a ponto de se encontrarem em curso os censos de suas duas unidades fundamentais, os Centros de Referência da Assistência Social (CRAS) e Centros de Referência Especializada da Assistência Social (CREAS). Também foi aprovada naquele ano a Tipificação Nacional dos Serviços Socioassistenciais. O SUAS já abarcava então mais de cinco mil CRAS e mil CREAS, distribuídos em praticamente todo o território nacional, com diferentes serviços estruturados nos dois níveis de proteção social - básica e especial. Esses serviços são financiados na modalidade inaugurada na assistência social com o SUAS, de transferência de recursos fundo a fundo, sendo muito mais ágil e consistente do que a lógica anterior de repasses via convênios.
De fato, esse avanço foi generalizado e constatado em todas as dimensões abarcadas pela TACGAS, com exceção somente da subdimensão recursos financeiros, a qual registrou decréscimo em sua pontuação. Em particular, esta deterioração deveu-se fundamentalmente à redução de quase $60 \%$, ou de 2.807 para 1.258 municípios que declararam não possuir vinculação legal no orçamento municipal para a área de assistência social. Como o período de 2005 a 2009 coincide com a grande expansão dos investimentos federais para a criação e consolidação do SUAS, por meio dos pisos de proteção social básica e especial custeados via Ministério do Desenvolvimento Social e Combate à Fome (MDS), esta piora no comprometimento local de recursos pode indicar um efeito crowding out ou substitutivo imprevisto entre recursos federais aportados e esforço orçamentário local na seara da assistência social.

No que concerne ao pressuposto de que a capacidade de gestão deve afetar a oferta de serviços, pode-se inicialmente verificar se realmente existe determinada correlação entre os níveis da TACGAS e o potencial de oferta de serviços socioassistenciais e ações correlatas. 
De fato, como revelam os gráficos seguintes, quanto melhor a capacidade de gestão em assistência social, maior é o percentual de oferta de serviços. Este resultado se mantém independentemente da caracterização dos serviços, se pertencentes à Proteção Social Básica, Especial ou de caráter geral, conforme três gráficos anteriores, e é aderente aos propósitos da TACGAS, ao denotar uma substancial influência da capacidade de gestão na disponibilização e prestação efetiva de uma ampla gama de serviços socioassistenciais. Somente no caso da operação do Cadastro Único pela gestão municipal, constata-se uma relativa constância em sua oferta pelos vários perfis de gestão, motivada pela sua quase universalização já àquela época5 ${ }^{5}$, o que inclusive reduziu o poder de discriminação dessa variável.

Ao se analisar os serviços de maior complexidade relativa, como o Programa de Erradicação do Trabalho Infantil (PETI), dentre outros, constata-se que sua oferta se intensifica à medida que o nível de gestão conforme a TACGAS aumenta. Isso sugere forte correlação entre a qualidade da estrutura para gestão da assistência social e a potencialidade de oferta de serviços de maior complexidade.

O cotejamento da TACGAS com o Índice de Desenvolvimento dos Centros de Referência de Assistência Social (IDCRAS) parece também validar a proposta metodológica aqui apresentada. O IDCRAS tem sido adotado como ferramenta de auxílio para os processos de produção e implementação de políticas públicas na área social, em especial no âmbito da proteção social básica. Grosso modo, este é um indicador sintético que avalia os CRAS dos municípios brasileiros, atribuindo-lhes uma pontuação em função de dimensões de análise específicas ${ }^{6}$. Há nítida correlação entre a evolução do IDCRAS e o comportamento da TACGAS. Nos municípios enquadrados nos dois primeiros perfis, em média seus respectivos CRAS situam-se nos estágios 4 e 5 dentre os 10 estágios de desenvolvimento destas unidades medidos pelo IDCRAS. Por seu turno, os CRAS situados em municípios de perfil avançado ou referencial alcançaram respectivamente, em média, os estágios 6 e 7 do IDCRAS.

Em suma, na análise de perfis progressivamente melhores de gestão municipal, constata-se em nível local uma presença cada vez maior e de melhor qualidade deste equipamento crucial para a assistência social que é o CRAS.

Essa correlação afigura-se relevante porque denota a influência potencial da capacidade de gestão não "somente" na gama e escala de serviços socioassistenciais ofertados, mas também na própria qualidade destes serviços ou, ao menos, na estruturação adequada de insumos e atividades para sua consecução. 


\section{GRÁFICO 6: PERCENTUAL DE OFERTA DE SERVIÇOS E UNIDADES DA PROTEÇÃO SOCIAL BÁSICA, POR NÍVEL TACGAS - 2009 (\%)}
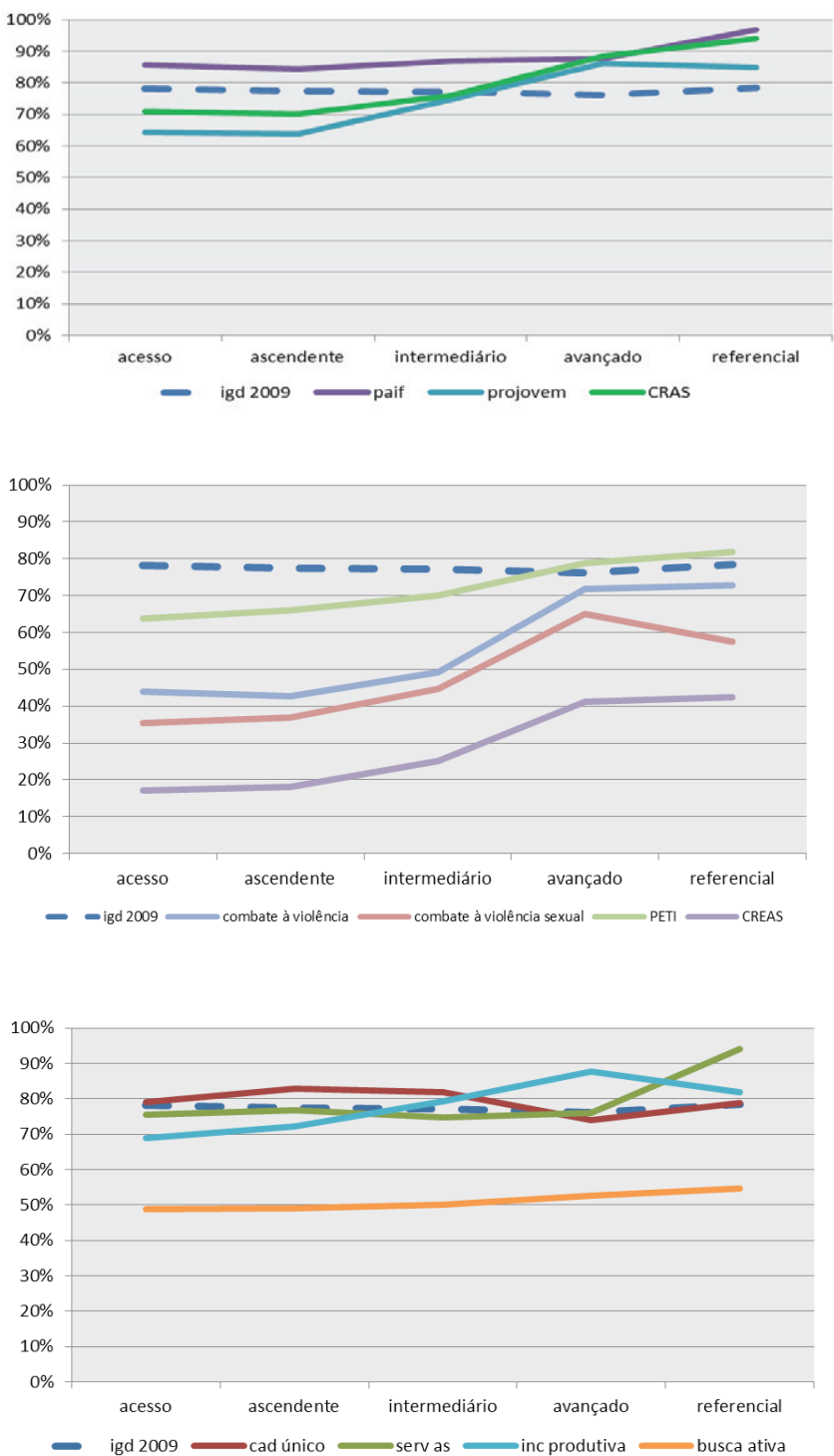

Fonte: Elaboração própria e IBGE, Munic 2009.

5 De acordo com a MUNIC AS 2009, 5.365 municípios já operavam o Cadastro Único naquele ano, dentre os 5.565 municípios brasileiros, ou 96,4\% do total.

6 Para mais detalhes sobre o IDCRAS, especialmente sua composição, dimensões e construção, vide "Monitoramento SUAS: censo CRAS 2008". Brasília, DF: Secretaria de Avaliação e Gestão da Informação, Secretaria Nacional de Assistência Social, 2010.

Revista Brasileira de Monitoramento e Avaliação | Número 3 | Janeiro-Junho de 2012 


\section{- GRÁFICO 7: PONTUAÇÃO IDCRAS AJUSTADO (2009) POR PERFIL DE GESTÃO TACGAS - 2009}

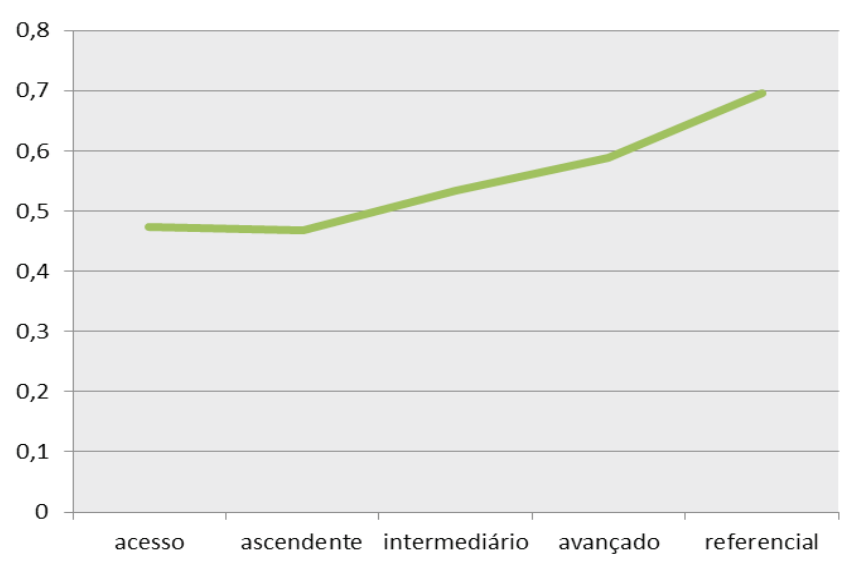

Fonte: Elaboração própria. 


\section{Considerações Finais}

Este trabalho objetivou delinear uma nova tipologia para mensuração da capacidade de gestão municipal em assistência social no País. Os resultados revelaram-se condizentes com o preconizado nos âmbitos técnico e acadêmico especializados, ao explicitar uma significativa correlação entre capacidade de gestão e oferta de serviços socioassistenciais. Destarte, investimentos destinados especificamente à melhoria da gestão, bem como sua consideração explícita no desenho e na implantação de políticas podem elevar consideravelmente a eficácia e efetividade dessas últimas.

Contudo, faz-se necessário enfatizar dois aspectos para o correto emprego da tipologia em questão. Em primeiro lugar, a forte interação entre gestão e disponibilização de serviços na seara da assistência social não exime a concorrência de outros fatores para a prestação destes serviços, inclusive de caráter geral, como nível de atividade econômica e infraes- trutura básica municipal, por exemplo. Secundariamente, o sentido de causalidade não está estabelecido, e a própria demanda por serviços pode ensejar o estabelecimento, ainda que precário, de serviços para seu atendimento, que por seu turno demandam ou estimulam o aperfeiçoamento da gestão, em um processo de interações mútuas.

Não obstante, ao fim e ao cabo a TACGAS mostrou-se consistente temporalmente, corroborando a importância das políticas desenvolvidas nos últimos anos no campo da assistência social. De fato, ao correlacionar-se forte e positivamente com a oferta de serviços, bem como abarcar diversos fatores preconizados pelo arcabouço normativo da assistência social, a TACGAS pode efetivamente subsidiar o direcionamento e a priorização da ação governamental, em especial na seleção de municípios para envidamento prioritário de esforços para a erradicação da miséria. 